\title{
Professional Radiation Protection Societies and the International Organizations - Exploiting the Synergies
}

Phil Metcalf

Radiation protection covers many disciplines from science through philosophy to law, and interacts with many human activities and endeavors. Professional societies for radiation protection were established and evolved throughout the second half of the twentieth century in many countries, and presently represent around twenty thousand professionals working in more than fifty countries. During the same period a number of international organizations were established, some devoted to radiation safety, others with a role to play in radiation safety; such organizations being either independent non-governmental organizations or intergovernmental organizations of both regional and international dimensions.

It was not many years after the establishment of national radiation protection societies that the society members realized the potential benefits of international exchange of ideas and experience, and in 1964 the International Radiation Protection Association (IRPA) was born. IRPA was established to promote both the profession of radiation protection globally and to promote professionalism in radiation protection. Since its inception IRPA has been providing a platform for exchange between its member societies and individual members. More recent developments have seen the establishment of regional groupings of IRPA affiliated societies such as the Asian Oceanic Radiation Protection Association, which have provided greater and more frequent opportunities for interaction and dialogue amongst radiation protection professionals.

The international organizations first started to evolve in the 1920's with the establishment of the International X-Ray Unit Committee (forerunner to the International Commission on Radiological Units - ICRU) and the International Radium Committee (forerunner to the International Commission on Radiation Protection - ICRP). The latter bodies were established when the potentially harmful affects of exposure to ionizing radiation became evident and the benefits of international collaboration in their investigation and control were realized. Following the Second World War and the increasing atmospheric testing of nuclear weapons the United Nations (UN) set up its Scientific Committee on the Effects of Atomic Radiation (UNSCEAR) due to concern about the build up of radioactivity in the environment. Increasing concern over the potential proliferation of nuclear weapons also led the United Nations establishing the International Atomic Energy Agency (IAEA). The IAEA was established to administer the Non Proliferation Treaty under which the five states possessing nuclear weapons undertook to transfer nuclear expertise to other countries for the safe and secure exploitation of nuclear technologies for peaceful purposes in exchange for an undertaking not to develop nuclear weapons. Amongst its various tasks, the IAEA was designated as the UN body to establish international safety standards for protection of health and property against the effects of ionizing radiation and also to provide for application of the standards.

As the use of nuclear energy developed and radiation was increasingly used throughout the world other UN agencies took up related responsibilities; the Pan American Health Organization and the World Health Organization identified the potential public health implications of environmental contamination, the International Labour Organization identified a role in the protection of workers against radiation in the working environment, and the Food and Agriculture Organization of the UN identified a role in respect of radioactive contamination in foodstuffs. Roles also became apparent for the international standards bodies and the 
International Standards Organization saw its role in measurement standards for radiological parameters and the International Electro Technical Commission a role in setting standards for instruments measuring radiation.

The nuclear and radiation technology related industries have also established a number of international and regional bodies to represent their interests and to engage with the international organizations. Such organizations include the World Nuclear Association, representing the nuclear industry, and the World Nuclear Transport Institute whose role is to represent the collective interests of the radioactive materials transport sector.

In undertaking their responsibilities for developing consensus on the effects of exposure to ionizing radiation and consensual standards on safety and the technical aspects necessary to demonstrate compliance with the standards, the various international bodies call upon experts from around the world to pool their knowledge and experience with a view to identifying modalities that will provide a high level of safety. Such processes need extensive consultation and broad peer review to be effective. Furthermore, the effective use and application of safety standards requires both awareness of the standards and an understanding of their content and basis. These processes can only be undertaken effectively if there is ongoing and frequent dialogue between the international organizations and radiation protection professionals in all spheres of the profession from researchers through safety assessors, practitioners, operators to regulators.

The national, regional and international radiation protection societies and associations have become the vehicle to provide this conduit from the profession to the international organizations. Increasingly, the IRPA international and regional congresses provide forums for all parties to engage in dialogue and for the synergies to be exploited.

\section{Phil Metcalf}

Phil Metcalf (pmetcalf@chello.at) was President of IRPA between 2004 and 2008, having served a total of sixteen years on the Executive Council of IRPA. He spent 28 years with the South African National Nuclear Regulator and was the Deputy General Manager before moving to the IAEA where he headed the Radioactive Waste and Spent Fuel Safety Unit for ten years. He chaired the IAEA Waste Safety Standards Committee from 1996 to 2001. He presently works as an independent nuclear and radiation safety consultant. 